\title{
Acute lung injury during antithymocyte globulin therapy for aplastic anemia
}

\author{
Ewan Christopher Goligher MD ${ }^{1}$, Christine Cserti-Gazdewich MD FRCPC ${ }^{2}$, Meyer Balter MD FRCPC $^{3}$, \\ Vikas Gupta MD MRCP FRCPath ${ }^{4}$, Joseph E Brandwein MD FRCPC ${ }^{4}$
}

\begin{abstract}
EC Goligher, C Cserti-Gazdewich, M Balter, V Gupta, JE Brandwein. Acute lung injury during antithymocyte globulin therapy for aplastic anemia. Can Respir J 2009;16(2):e3-e5.

The case of a 33-year-old man with aplastic anemia who experienced recurrent episodes of hypoxemia and pulmonary infiltrates during infusions of antithymocyte globulin (ATG) is described. With the use of high-dose corticosteroids, the patient's original episodes resolved, and were subsequently prevented before additional administrations of ATG. Rare reports of an association between ATG and acute lung injury are found in the literature, but this is the first report of successful steroid-supported re-exposure. Although the mechanism of ATG-related acute lung injury remains uncertain, it may be parallel to the mechanism of transfusionrelated acute lung injury because the pathogenesis of the latter relies, in part, on antileukocyte antibodies. ATG-related toxicity should be included in the differential diagnosis of new, infusion-associated pulmonary infiltrates, and corticosteroids may be a useful therapeutic consideration in the management.
\end{abstract}

Key Words: Acute lung injury; Antithymocyte globulin; Aplastic anemia; Transfusion-related acute lung injury

$\Delta$ ntithymocyte globulin (ATG) is an immunosuppressant drug used in treating aplastic anemia and solid organ transplant rejection. Adverse effects commonly include infusional fever, chills, urticaria and less often, a serum sickness reaction one to two weeks later $(1,2)$. Anaphylactic or anaphylactoid reactions may occur idiosyncratically, sometimes presenting with bronchoconstrictive respiratory distress. However, case reports on isolated acute lung injury have also been published over the past two decades (3-7). We describe a case of successfully treated ATG-induced acute lung injury and review the speculated pathogenesis, offering a new perspective on parallels with transfusion-related acute lung injury (TRALI).

\section{CASE PRESENTATION}

A 33-year-old African-Canadian man presented in March 2007 with jaundice (bilirubin $252 \mu \mathrm{mol} / \mathrm{L}$ ) and elevated aminotransferases (aspartate aminotransferase $1667 \mathrm{U} / \mathrm{L}$, alanine aminotransferase $2203 \mathrm{U} / \mathrm{L}$ ). Liver biopsy demonstrated cholestatic hepatitis - serology-negative for hepatitis A, B and C. Over the ensuing two months, he developed progressively worsening pancytopenia (hemoglobin $85 \mathrm{~g} / \mathrm{L}$, white blood cell count $1.9 \times 10^{9} / \mathrm{L}$, neutrophils $0.9 \times 10^{9} / \mathrm{L}$, platelets $2 \times 10^{9} / \mathrm{L}$,

\section{Atteinte pulmonaire aiguë durant un traitement par globulines antithymocytes pour une anémie aplasique}

\begin{abstract}
On décrit ici le cas d'un homme de 33 ans atteint d'anémie aplasique qui a manifesté des épisodes récurrents d'hypoxémie et des infiltrats pulmonaires lors de perfusions de globulines antithymocytes (GAT). Grâce à l'administration de corticostéroïdes à forte dose, les premiers épisodes ont pu être traités et les suivants ont pu être prévenus avant l'administration des traitements subséquents par GAT. La littérature fait état de quelques rapports citant un lien entre les GAT et l'atteinte pulmonaire aiguë, mais il s'agit du premier rapport selon lequel il a été possible d'administrer de nouveau des GAT avec succès grâce à une corticothérapie d'appoint. Bien que le mécanisme qui sous-tend l'atteinte pulmonaire aiguë liée aux GAT demeure inconnu, on pourrait le mettre en parallèle avec celui qui sous-tend l'atteinte pulmonaire aiguë liée aux transfusions, car la pathogenèse de cette dernière repose en partie sur les anticorps antileucocytaires. La toxicité liée aux GAT pourrait être incluse dans le diagnostic différentiel des infiltrats pulmonaires d'apparition récente associés aux perfusions et la corticothérapie pourrait être une option thérapeutique utile pour leur prise en charge.
\end{abstract}

reticulocytes $13 \times 10^{9} / \mathrm{L}$ ). Bone marrow biopsy showed hypocellularity without dysplasia or infiltrates; paroxysmal nocturnal hemoglobinuria screen was negative. There was no cardiorespiratory history. Baseline computed tomography (CT) scan of the chest was normal.

Hepatitis-associated aplastic anemia was diagnosed and equine ATG initiated (Atgam, Pharmacia \& Upjohn, USA) $40 \mathrm{mg} / \mathrm{kg}$ intravenously daily for four days. Before each ATG infusion (total volume $1.2 \mathrm{~L}$ ), he was premedicated with hydrocortisone $100 \mathrm{mg}$ and diphenhydramine $50 \mathrm{mg}$ intravenously. The first infusion was uneventful. Near to the end of the second ATG infusion (day 2), he complained of chest tightness, chills and rigors. His temperature rose to $38.5^{\circ} \mathrm{C}$ and over several hours the $\mathrm{O}_{2}$ saturation dropped to $91 \%$ while breathing ambient air, corrected with $\mathrm{O}_{2}$ at $3 \mathrm{~L} / \mathrm{min}$ by nasal prongs. Blood pressure was $120 / 60 \mathrm{mmHg}$ and jugular venous pulsations were not elevated. Blood, sputum and urine cultures were negative. Piperacillin/tazobactam and ciprofloxacin were started for febrile neutropenia. He was empirically given intravenous furosemide without clinical improvement.

The third infusion of ATG (day 3) was administered on schedule, but the infusion rate was slowed from $100 \mathrm{~mL} / \mathrm{h}$ to

\footnotetext{
${ }^{1}$ Department of Medicine, University of Toronto; ${ }^{2}$ Department of Laboratory Hematology; ${ }^{3}$ Department of Medicine, Mount Sinai Hospital; ${ }^{4}$ Department of Hematology, Princess Margaret Hospital, Toronto, Ontario

Correspondence: Dr Meyer Balter, Mount Sinai Hospital, Asthma Prevention Clinic, Suite 6 207, 600 University Avenue, Toronto, Ontario M5G 1X5. Telephone 416-586-4800 ext 4663, fax 416-586-4736, e-mail mbalter@mtsinai.on.ca
} 


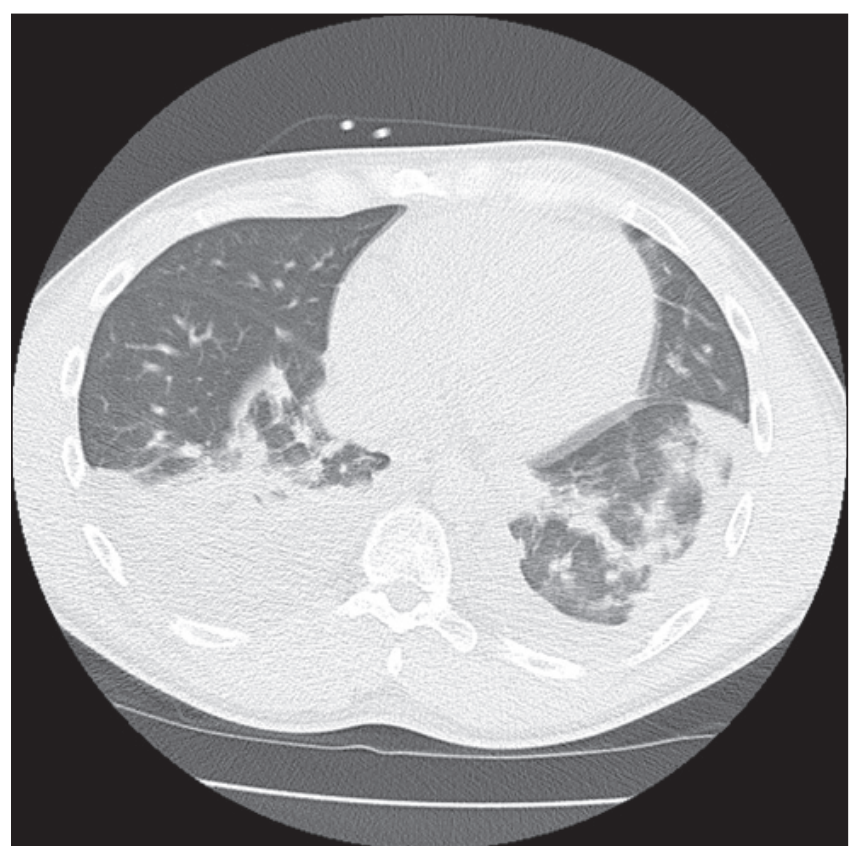

Figure 1) Computed tomography of the chest after the third infusion of antithymocyte globulin demonstrates bilateral pleural effusions and diffuse ground glass opacities

$70 \mathrm{~mL} / \mathrm{h}$. Two hours into infusion, his temperature rose to $39^{\circ} \mathrm{C}$ and his hypoxemia worsened $\left(\mathrm{O}_{2}\right.$ saturation $81 \%$ on room air). He became increasingly dyspneic, requiring face mask $\mathrm{O}_{2}$ (fraction of inspired $\mathrm{O}_{2}, 32 \%$ ) to maintain saturations above $95 \%$. He denied cough, chest pain or hemoptysis, but reported mild diffuse myalgias and arthralgias. An additional dose of hydrocortisone $100 \mathrm{mg}$ was administered intravenously and he improved over the next several hours, defervescing and discontinuing the supplemental $\mathrm{O}_{2}$. CT scan of the chest revealed diffuse bilateral patchy areas of consolidation with ground glass opacities (Figure 1). Because of the rapid improvement, bronchoscopy was not performed.

Pre-emptive doses of hydrocortisone $100 \mathrm{mg}$ were administered intravenously before and during the fourth infusion (day 4). Two hours into the infusion of ATG, the patient's dyspnea and hypoxemia relapsed, requiring supplemental face mask $\mathrm{O}_{2}$. He remained afebrile. Hours later, he complained of sharp, pleuritic chest pain. Auscultation revealed faint bilateral inspiratory crackles in the lower lobes. Jugular venous pulsations were visible $2 \mathrm{~cm}$ above the sternal angle. There was no electrocardiographic evidence of myocardial ischemia or infarct, and symptoms resolved several hours after the ATG infusion was completed.

A repeat CT of the chest obtained four days later revealed complete resolution of pulmonary infiltrates. No further episodes of fever, dyspnea or hypoxemia were observed after ATG was completed.

\section{DISCUSSION}

We report dyspnea and pulmonary infiltrates associated with ATG in a patient with aplastic anemia. While causes of pulmonary infiltrates are numerous, several features support an association with ATG in the present case. The temporal association of rapid-onset infiltrates with ATG infusion was striking. Relapsing acute lung injury on the second and subsequent infusions was also consistent with the pattern observed in previous reports of ATG-associated lung injury $(3,5,7)$. Once the ATG regimen was completed, the patient experienced no further symptoms and the infiltrates resolved rapidly.

Infection was an unlikely cause of the patient's pulmonary infiltrates. While the patient was at a high risk for opportunistic infection due to aplastic immune compromise, he did not report having any respiratory infections in any of the vulnerable preceding three months of neutropenia. ATG has been associated with an increased risk of serious infection (8), but the precise coincidence of infiltrates with ATG treatment and their rapid resolution argue against infection. Although bronchoalveolar lavage was deferred, all sputum samples were culture-negative.

Cardiogenic pulmonary edema as the pathological correlate of transient pulmonary infiltrates was considered, but deemed unlikely because of the absence of pre-existing cardiac disease. The total volume and rate of ATG infusion were also too low to induce circulatory overload. Moreover, symptoms recurred despite slowing the ATG infusion. The jugular venous pressure was never elevated and the dyspnea was diuretic-refractory. Peripheral edema also developed throughout the first week, with a significant weight gain of approximately $10 \mathrm{~kg}$. This fluid retention persisted after the resolution of the respiratory symptoms in a manner independent of the infusion-associated pulmonary capillary leak. The dyspnea and hypoxemia were also associated with systemic symptoms of arthralgias, myalgias, chills and fevers (documented), suggesting a systemic inflammatory process.

The role of blood products (eg, TRALI) was also reviewed because of the patient's dependence on red blood cell and platelet transfusions. However, he had never experienced dyspnea or chest discomfort within $6 \mathrm{~h}$ of any transfusion, and continued to receive transfusions uneventfully after completing ATG.

An association between ATG and acute lung injury was first described in an experimental model in 1975 (9). Four of five case reports over the next two decades described severe lung injury that progressed to acute respiratory distress syndrome (ARDS) and required intensive care unit admission (3-6). The fifth case described recurrent transient pulmonary infiltrates associated with ATG challenges and rapid recovery when ATG was withdrawn (7). One large retrospective analysis (10) of over 42,000 national registry renal transplant patients revealed that ATG, when given for graft rejection, represented the only variable associated with an increased risk of ARDS (OR 3.85). Thus, in rare cases, ATG is responsible for a spectrum of lung injuries varying from transient infiltrates to full-blown ARDS. In the present case, we wish to confirm and extend previous observations about this relatively unknown adverse effect of ATG.

Little is known about the mechanism of ATG-induced lung injury. ATG contains antibodies of animal origin, which are active against human $\mathrm{T}$ lymphocyte antigens (1). Human antileukocyte antibodies play a hypothesized role in TRALI. In vitro and in vivo evidence increasingly support a pathogenesis beginning with the direct binding of antibodies to leukocytes, with cellular activation, degranulation and respiratory burst responses damaging to pulmonary endothelium (11). Although the isolated antileukocyte antibodies initially reported were 
neutrophil-specific, more recently, monocytes (12) and lymphocytes (13) have also been implicated. Whether antileukocyte antibodies of animal origin can recapitulate these observations is not yet known. It is possible that the pathophysiology of lung injury induced by ATG is congruent with and supportive of the antigen-antibody hypothesis of TRALI. ATG-induced lung injury, such as TRALI, does not occur in all cases in which a cognate immune interaction is present (14). TRALI seems to require either a patient predisposition and/or a 'second-hit' priming event (15), and the infrequency of acute lung injury secondary to ATG may similarly be multifactorial.

There are other possible mechanisms to explain acute lung injury. A cytokine release syndrome, well appreciated in the use of ATG and OKT3, may also play a role in the development of pulmonary edema (16). Pulmonary capillary endothelial permeability increases in response to tumour necrosis factor-alpha, interleukin-1 and interleukin- 8 released from damaged or activated lymphocytes, similar to the pathogenesis of ARDS in sepsis (17). Alternatively, ATG may cause direct pulmonary cytotoxicity. ATG has been observed to bind nuclear and cytoplasmic components of lung in vitro (18). A complement-mediated acute hemorrhagic pulmonary lung lesion in an animal model was reported by Haefen et al (9); interestingly, this lesion was prevented by absorption of serum with homogeneous suspensions of lung and thymus, suggesting that the reaction was due to direct antibody-mediated cytotoxicity. The literature on this subject is very limited and further basic and clinical investigations are required to clarify the mechanism of acute lung injury associated with ATG.

It is unclear why the acute lung injury episodes in the present case were more transient and less severe than those of the previous reported cases. After the first episode of hypoxemia

\section{REFERENCES}

1. Cosimi AB. The clinical value of antilymphocyte antibodies. Transplant Proc 1981;13:462-8.

2. Pfizer product monograph: Atgam ${ }^{\circledR}($ lymphocyte immune globulin, anti-thymocyte globulin [equine] sterile solution). $<$ http://media. pfizer.com/files/products/uspi_atgam.pdf $>$ (Version current at September 12, 2007)

3. Murdock DK, Lawless CE, Collins E, Huml JP, Pifarre R. ARDS following equine ATG therapy. Chest 1987;92:578

4. Dean NC, Amend WC, Matthay MA. Adult respiratory distress syndrome related to antilymphocyte globulin therapy. Chest 1987;91:619-20.

5. Zomas A, Marsh JC, Harrison NK, et al. Rapid progression of fibrosing alveolitis and thyrotoxicosis after antithymocyte globulin therapy for aplastic anemia. Ann Hematol 1995;71:49-51.

6. Walton GD, Gualtieri RJ. Antithymocyte globulin-induced adult respiratory distress syndrome. Arch Intern Med 1998;158:1380.

7. Maillard N, Foucher P, Caillot D, Durand C, Sgro C, Camus P. Transient pulmonary infiltrates during treatment with antithymocyte globulin. Respiration 1999;66:279-82.

8. Bacigalupo A, Lamparelli T, Bruzzi P, et al. Antithymocyte globulin for graft-versus-host disease prophylaxis in transplants from unrelated donors: 2 randomized studies from gruppo italiano trapianti midollo osseo (GITMO). Blood 2001;98:2942-7.

9. Haefen UH, Martins AC, Aranjo MA, Ferraz AS, Ciconelli J, Bohm GM. [Diffuse immunological lung damage due to heterologous anti-thymocyte serum.] Langenbecks Arch Chir 1975;(Suppl):153-6.

10. Shorr AF, Abbott KC, Agadoa LY. Acute respiratory distress syndrome after kidney transplantation: Epidemiology, risk factors, and outcomes. Crit Care Med 2003;31:1325-30. (with the second ATG infusion), we elected to continue ATG, believing initially that an infectious process was the likely cause. The infusion protocol was slowed and an extra dose of Solu-Cortef (Pfizer, Canada) was administered during the next episode of dyspnea and hypoxemia (with the third ATG infusion). As such, the hypoxemia resolved over the subsequent $12 \mathrm{~h}$. Extra doses of hydrocortisone were given in anticipation of the fourth ATG infusion, and the subsequent episode of dyspnea and hypoxemia was even shorter than the previous. These regimen responses may have ameliorated the severity of the lung injury.

The present case and the mechanisms behind ATGmediated acute lung injury raise important considerations for the diagnosis and management of this severe adverse effect. ATG should be considered a potential cause of acute hypoxemia or pulmonary infiltrates, and lists of medications known to cause respiratory disorders should be updated to include ATG $(19,20)$. In cases of suspected acute lung injury during an ATG infusion, there may be value or interest in submitting serum for lymphocytoxicity assays used in the serological workup of suspected TRALI reactions to compare $\mathrm{T}$ cellspecific reactivities with other cases.

The management of these cases must be based on sound clinical judgment. Deciding whether to continue ATG is difficult, and should be based on the severity and progression of the lung injury. Slowing the infusion and administering additional doses of corticosteroids may limit progression of lung injury and facilitate regimen completion.

CONFLICTS OF INTEREST: None of the authors have any potential or actual financial conflicts of interest to disclose.

11. Toy P, Lowell C. TRALI - definition, mechanisms, incidence and clinical relevance. Best Pract Res Clin Anaesthesiol 2007;21:183-93

12. Kopko PM, Paglieroni TG, Popovsky MA, Muto KN, MacKenzie MR, Holland PV. TRALI: Correlation of antigenantibody and monocyte activation in donor-recipient pairs. Transfusion 2003;43:177-84

13. Newman RS, Williams JH, Moberg LJ, Cook ML. Postpartum immunologic-mediated pulmonary edema associated with transfusion of blood containing an anti-B-lymphocyte antibody. West J Med 1989;150:584-6.

14. Silliman CC, Ambruso DR, Boshkov LK. Transfusion-related acute lung injury. Blood 2005;105:2266-73.

15. Silliman CC, Curtis BR, Kopko PM, et al. Donor antibodies to HNA-3a implicated in TRALI reactions prime neutrophils and cause PMN-mediated damage to human pulmonary microvascular endothelial cells in a two-event in vitro model. Blood 2007;109:1752-5.

16. Costanzo-Nordin MR. Cardiopulmonary effects of OKT3: Determinants of hypotension, pulmonary edema, and cardiac dysfunction. Transplant Proc 1993;25(Suppl 1):21-4.

17. Martin TR. Lung cytokines and ARDS: the Roger S. Mitchell Lecture. Chest 1999;116(1 Suppl):2S-8S.

18. Greco B, Bielory L, Stephany D, et al. Antithymocyte globulin reacts with many normal human cell types. Blood 1983;62:1047-54.

19. Ben-Noun L. Drug-induced respiratory disorders: Incidence, prevention and management. Drug Saf 2000;23:143-64.

20. Camus P. Respiratory disease induced by drugs. Eur Respir J 1997;10:260-4. 


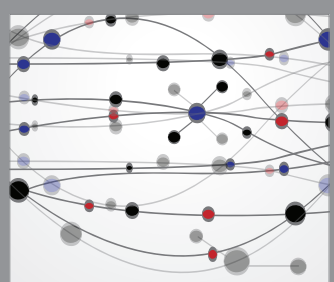

The Scientific World Journal
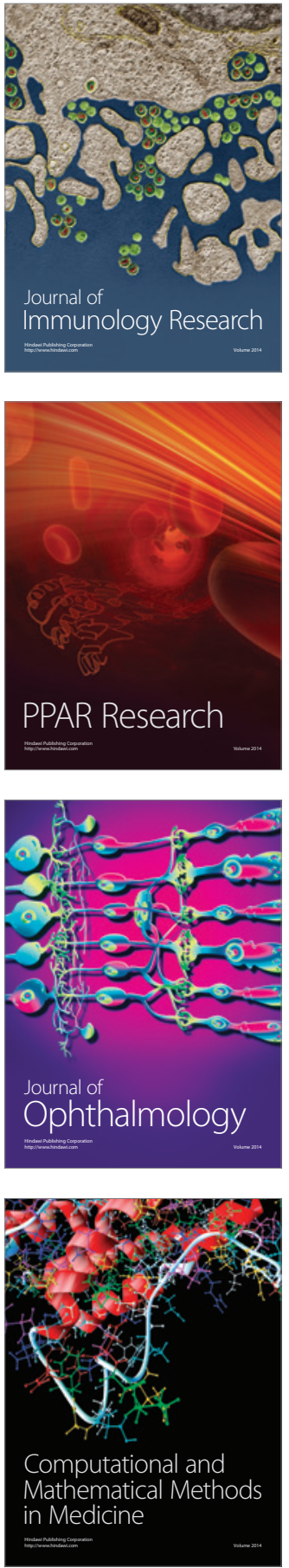

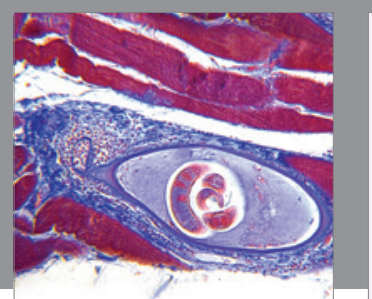

Gastroenterology Research and Practice

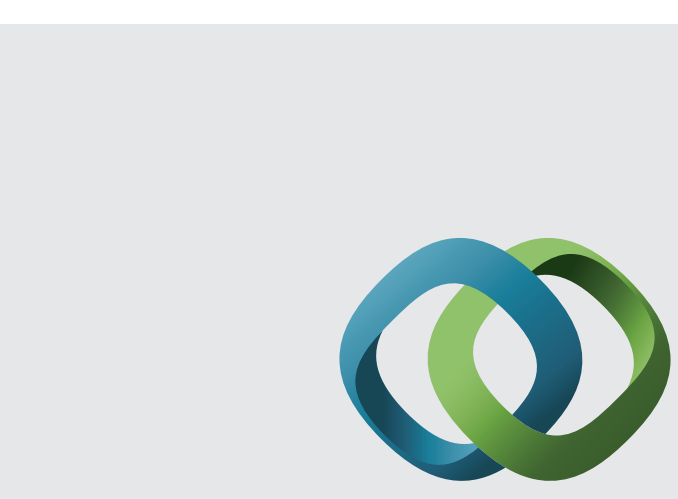

\section{Hindawi}

Submit your manuscripts at

http://www.hindawi.com
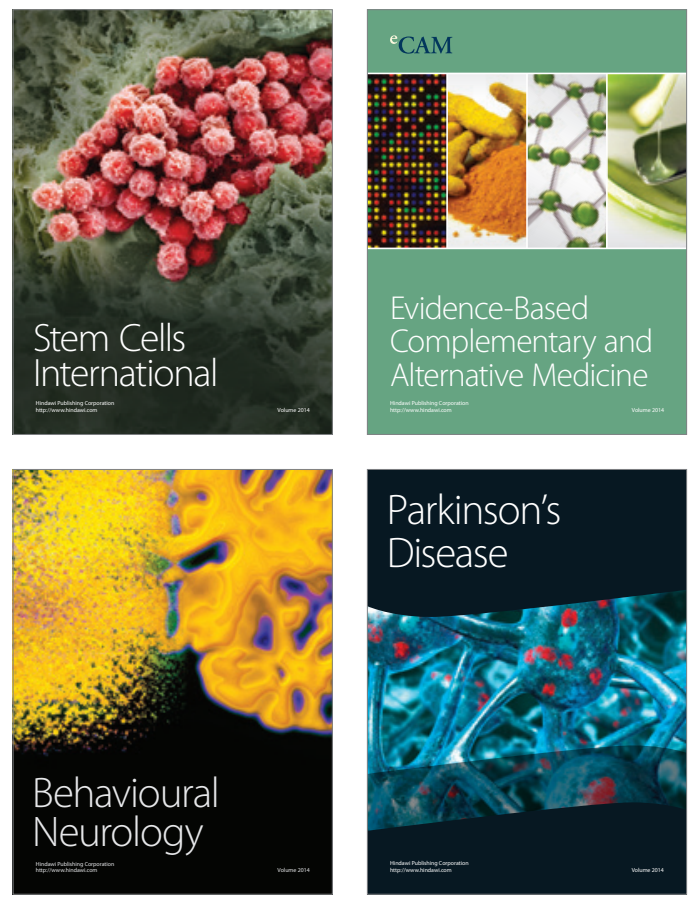
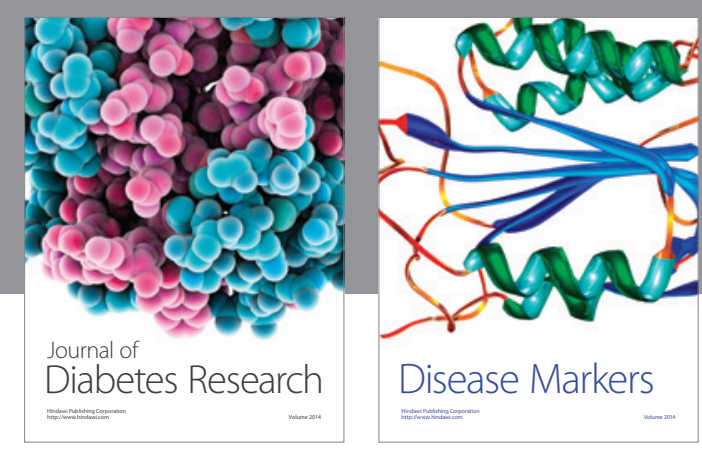

Disease Markers
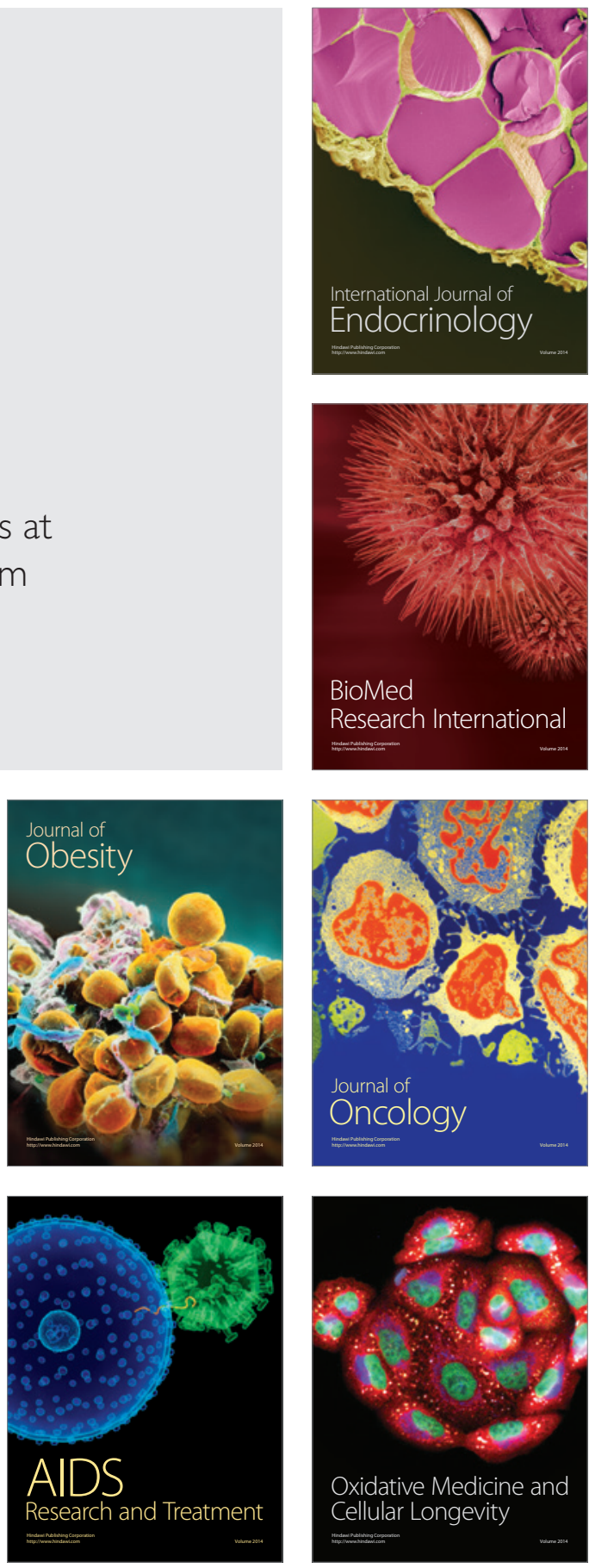